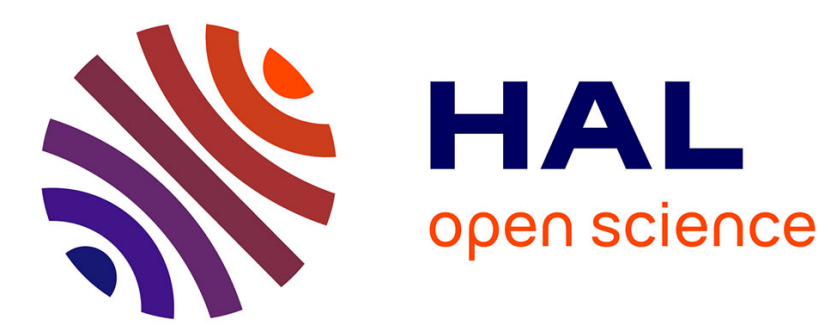

\title{
Phase transitions of saturated triglycerides
}

\author{
F. Lavigne, C. Bourgaux, M. Ollivon
}

\section{To cite this version:}

F. Lavigne, C. Bourgaux, M. Ollivon. Phase transitions of saturated triglycerides. Journal de Physique IV Proceedings, 1993, 03 (C8), pp.C8-137-C8-140. 10.1051/jp4:1993825 . jpa-00252256

\section{HAL Id: jpa-00252256 https://hal.science/jpa-00252256}

Submitted on 1 Jan 1993

HAL is a multi-disciplinary open access archive for the deposit and dissemination of scientific research documents, whether they are published or not. The documents may come from teaching and research institutions in France or abroad, or from public or private research centers.
L'archive ouverte pluridisciplinaire HAL, est destinée au dépôt et à la diffusion de documents scientifiques de niveau recherche, publiés ou non, émanant des établissements d'enseignement et de recherche français ou étrangers, des laboratoires publics ou privés. 


\title{
Phase transitions of saturated triglycerides
}

\author{
F. LAVIGNE, C. BOURGAUX* and M. OLLIVON
}

Physicochimie des Systèmes Polyphasés, URA 1218 du CNRS, 92296 Chatenay-Malabry, France * L.U.R.E., Bât. $209 \mathrm{D}$ Université Paris-Sud, 91405 Orsay, France

\begin{abstract}
The $\alpha->\beta$ phase transition of Tristearin (SSS) has been investigated both by Differential Scanning Calorimetry and Small Angle $X$-Ray Diffraction as a function of temperature at the same heating rate $(2 \mathrm{deg} / \mathrm{min})$ in order to elucidate either this transition occurs in the solid state or is melt mediated.
\end{abstract}

\section{INTRODUCTION}

Triglycerides display a complex monotropic polymorphism. They frequently exhibit from 3 to 6 crystalline varieties, the occurence of which depends on the nature of the fatty acid chains esterified on the glycerol molecule, crystallization procedure (melt cooling or solvent mediation), and samples purity. These crystals are made by the stacking of triglyceride layers, the thickness of which depends on the length and insaturation of the fatty acid chains, and their angle of tilt with respect to the basal planes formed by the methyl end groups (figure 1). These thicknesses, also called "long spacings", can be measured by Small Angle X-Ray Diffraction at $0<q<0.9 \AA^{-1}$. The lateral packing of the aliphatic chains (crystalline subcell) (figure 2 ) is characterized by "short spacings" at $0.9<q<1.8 \AA^{-1}$.

Transitions between these polymorphic varieties are irreversible and only possible when leading to the formation of more stable species (monotropism). The very fast kinetics observed for transitions between short chain compounds didn't allow to decide whether true melting takes place or whether the transitions occur in the solid state [1]. However, monotropism implies that these transitions occur via the melting of the most stable species. In order to investigate these mechanisms, slower transitions between polymorphic species of a long chain triglyceride (tristearin:SSS) have been studied. One of them will be presented here.

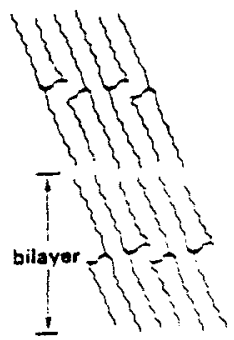

Fiqure 1 - Examples of bilayer triglyceride packings llong spacingsl.
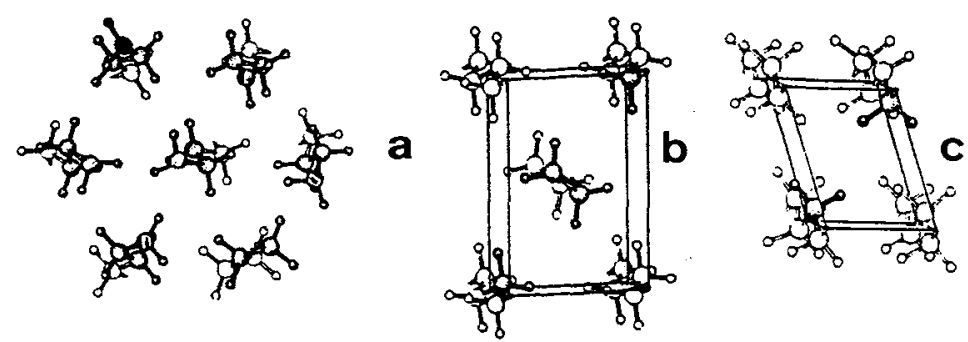

Fiqure 2 - Schematic representation of possible chain packings of long chains compounds: (a) Hexagonal packing, (b) Orthorhombic packing $\left(O_{1}\right)$. (c) Triclinic packing $\left(T_{i l}\right)$. (short spacings). 


\section{MATERIAL AND METHODS}

Tristearin has been synthesized and purified at the laboratory (purity $99.9 \%$ ) [2].

The $\alpha-->\beta$ transition is recorded by DSC (DSC-4 Perkin-Elmer calorimeter) at a heating rate of $+2{ }^{\circ} \mathrm{C} / \mathrm{min}$. $10 \mathrm{mg}$ of melted tristearin is placed in a sealed aluminium pan and rapidly quenched from 90 to $20^{\circ} \mathrm{C}$ to get $\alpha$ form.

For X-Ray Diffraction, $\alpha$ form has been prepared by rapid quenching of the melt from $90^{\circ} \mathrm{C}$ to $5^{\circ} \mathrm{C}$. 20 frames of 45 seconds are recorded as a function of temperature in the $q=0.005 \AA^{-1}$ $\left(\Theta=0.04^{\circ}\right)$ to $q=1.855 \AA^{-1}\left(\Theta=13.73^{\circ}\right)$ range using $D 24$ high flux of L.U.R.E as X-Ray source

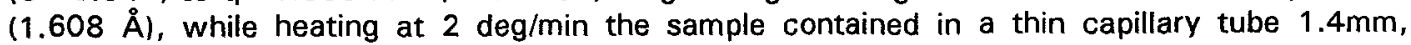
$0.01 \mathrm{~mm}$ walls. Heating is monitored by Eurotherm $902 \mathrm{P}$ temperature controller using $2 \times 0.2 \mathrm{~mm}$ type $E$ thermocouple as a sensor. In order to minimize the temperature deviations from linear increase versus time during heating, thermocouple was located between the sample and the heating device rather than very close to the sample. The thermal gradient created by this set-up resulted in a temperature lag between recorded and sample temperature which has been evaluated to be about $+1^{\circ} \mathrm{C}$. A 1024 channels gas-filled one-dimensional position sensitive detector is used for data collection.

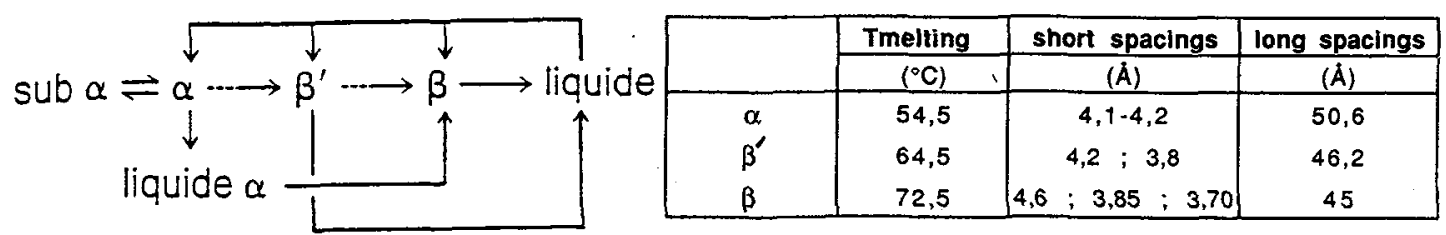

Fiqure 3 - Transitions between polymorphic varieties of SSS.
Table 1 - Thermal and structural features of SSS polymorphs [3].

\section{RESULTS AND DISCUSSION}

Trisaturated triglycerides generally crystallize under 3 main polymorphs called $\alpha, \beta$, and $\beta$. Alpha, which is the less stable form, is obtained by rapid quenching of the melt. Chains are vertical and hexagonaly packed with almost statistical orientation. The slow melting of this unstable species leads to the formation of the most stable variety $\beta$, the subcell of which is triclinic parallel $(T / /)$, while annealing of the supercooled liquid down to close to the melting point of $\alpha$ yields $\beta^{\prime}$ species. This last exhibits a meiting point intermediate between $\alpha$ and $\beta$ and orthorhombic perpendicular $\left(O_{\perp}\right)$ subcell. Both $\beta^{\prime}$ and $\beta$ present tilted chains. The main features of these SSS polymorphs are summarized in Table I [3]. Possible transitions between SSS polymorphs are summarized in figure 3 . The process of $\alpha-\cdots \beta$ transition of SSS has been investigated by both X-Ray Diffraction and Differential Scanning Calorimetry as a function of temperature at the same heating rate.

Figure 4 represents the $\alpha->\beta$ transition of SSS recorded at $2 \mathrm{deg} / \mathrm{min}$ by DSC. The melting of $\alpha$, which starts at $53.4^{\circ} \mathrm{C}\left(\max : 54.9^{\circ} \mathrm{C}\right.$ ), is immediately followed by a broad exotherm spreading until about $64^{\circ} \mathrm{C}$. The overlapping of $\alpha$ melting and subsequent $\beta$ recrystallization results in a complex recording in which both events partially neutralize each other. The small exothermic bump observed at about $61^{\circ} \mathrm{C}$ corresponds to the melting of some $\beta^{\prime}$ variety transiently formed between 55 and $61^{\circ} \mathrm{C}$ and its subsequent and immediate recrystallization into $\beta$. The melting of this last polymorph finally occurs at about $71^{\circ} \mathrm{C}$ (max: $72.1^{\circ} \mathrm{C}$ ). 


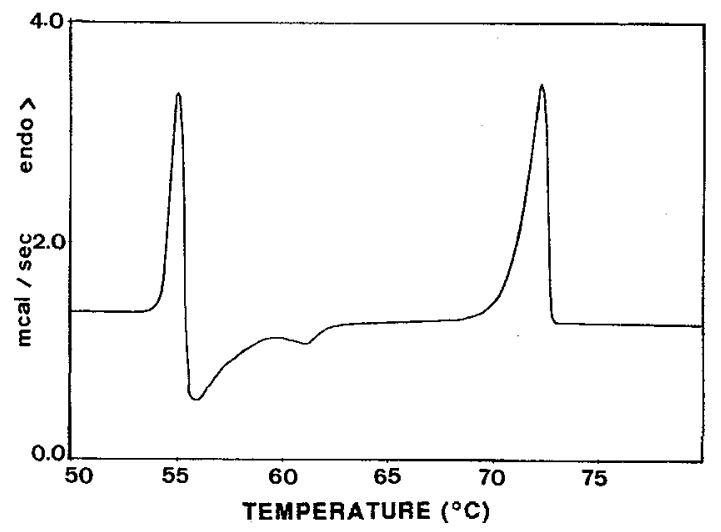

Figure 4 - DSC recording of $\alpha \rightarrow \beta$ transition of SSS. Heating rate $=2 \mathrm{deg} / \mathrm{min}$.

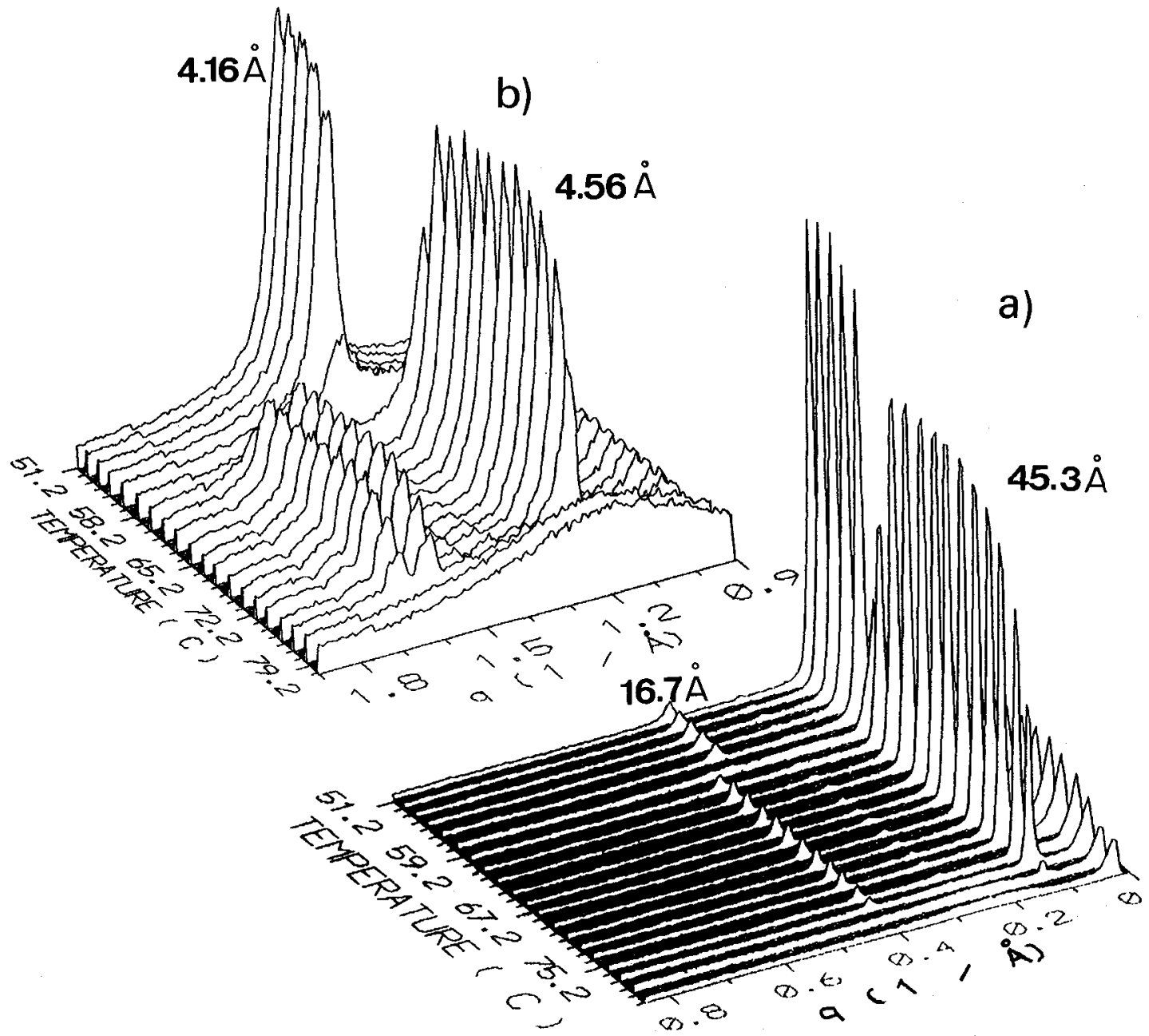

Figure 5 - Evolution of long (a) and short (b) spacings during the $\alpha-->\beta-->$ liquid transitions of SSS. Heating rate $=2 \mathrm{deg} / \mathrm{min}$. Short and long spacings are presented as $3 D$ plots versus temperature. 


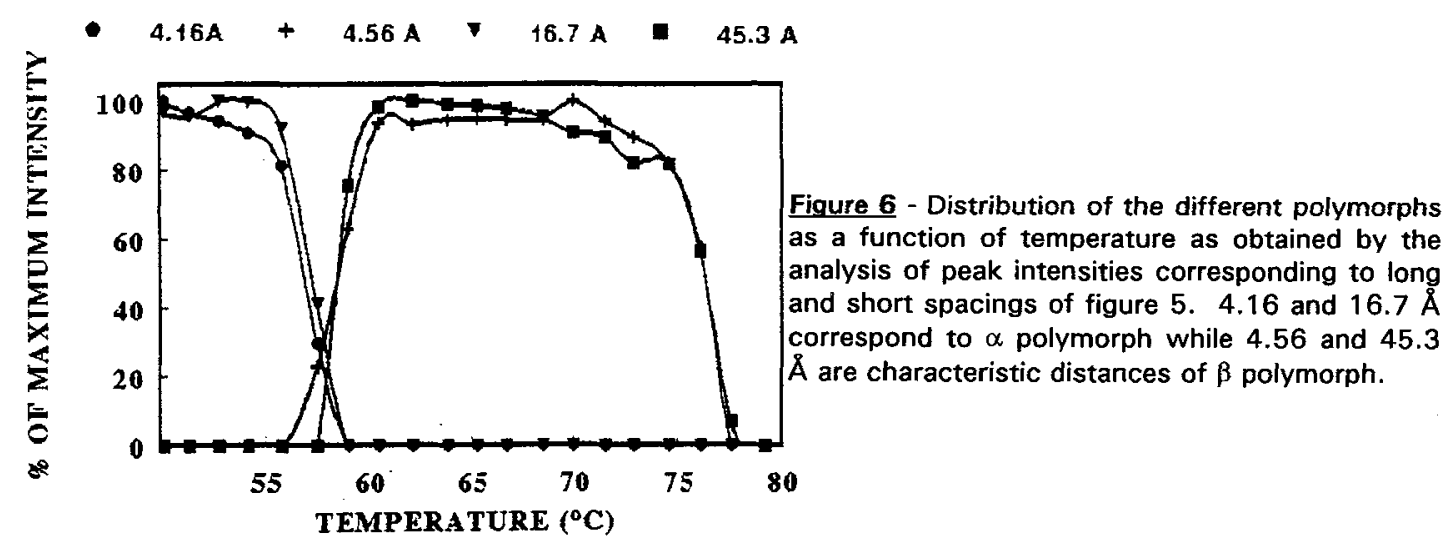

Figures $5 a$ and $5 b$ show the dynamic diffraction patterns corresponding to the $\alpha->\beta$ transition of SSS heated in the same conditions than for DSC measurements. Below $55^{\circ} \mathrm{C}$, short spacings indicate a single sharp peak at $4.16 \AA$ characteristic of $\alpha$ subcell, while long spacings pattern show a main diffraction line at $50.1 \AA$ with its second and third orders $(25.7$ and $16.7 \AA$ respectively). From 53.8 to $58.5^{\circ} \mathrm{C}$, intensities of the 16.7 and $50.1 \AA$ peaks simultaneously vanish as shown by figure 6 , while a new set of long $(45.3 \AA(n=1)$ and $15.1 \AA(n=3))$ and short $(4.6,3.9$, and $3.8 \AA$ ) spacings appears and is close to previously observed values for $\beta$ SSS (table 1). This temperature range of $\alpha$ melting correlates nicely with the DSC recording (taking account of the thermal lag, see Material and Methods). As shown by figure 6, intensities of these new peaks increase from $60^{\circ} \mathrm{C}$ and reach their maxima around $62^{\circ} \mathrm{C}$, which is in good agreement with the temperature range of the recrystallization exotherm of figure 4 . This overall $\alpha->\beta$ transition is similar to those recently reported for PPP by KELLENS et al. [4].

Final melting of $\beta$ form starts at around $70^{\circ} \mathrm{C}$ for short and long spacings, and at $78^{\circ} \mathrm{C}$ broad diffusion peaks of the melt can be seen in both figures, corresponding to an incomplete disorganization of the liquid state. One can notice in figure 5 a that the same diffusion pattern appeared between the melting of $\alpha$ form and recrystallization of $\beta$ form, which supports the hypothesis of solid-liquid-solid polymorphic transitions of triglycerides. Moreover, the recording by DSC of an endothermic peak before the exotherm corresponding to the formation of $\beta$ clearly indicates that $\beta$ recrystallizes from $\alpha$-melt rather than directly from $\alpha$ itself.

\section{CONCLUSION}

Small Angle X-Ray Diffraction using synchrotron high intensity beam allowed us to observe dynamically phase transitions of SSS. Differential Scanning Calorimetry recordings nicely correlate observed phase changes. Moreover, it seems that saturated long chain triglycerides exhibit solid-liquid-solid transitions intead of the apparent solid-solid phase changes of short chains compounds. Similar study on unsaturated long chain triglycerides shoud be very useful in trying to understand their much more complex polymorphism.

This work is supported by ARILAIT.

\section{REFERENCES}

[1] LARSSON K., The Lipid Handbook, Chapter 8, F.D. Gunstone, J.L. Harwood, F.B. Padley ed., Chapman and Hall, 1986.

[2] OLLIVON M., PERRON R., Chem. Phys. Lipids, 25(1979) 395-414.

[3] SMALL D.M., The Physical Chemistry of Lipids, Plenum Press, 1986.

[4] KELLENS M., MEEUSSEN W., RIEKEL C., and REYNAERS H., Chem. Phys. Lipids, 52(1990) 79-98. 